\title{
ESQUEMES EMOCIONALS EN UN GRUP DE PACIENTS DEPRESSIUS D'UN HOSPITAL DE LA CIUTAT DE LIMA ESQUEMAS EMOCIONALES EN UN GRUPO DE PACIENTES DEPRESIVOS DE UN HOSPITAL DE LA CIUDAD DE LIMA
} EMOTIONAL SCHEMAS OF DEPRESSED PATIENTS IN A HOSPITAL OF MENTAL HEALTH IN THE CITY OF LIMA

\author{
Paul Roger Brocca Alvarado* \\ Mirian Grimaldo Muchotrigo**
}

DOI: 10.7203/anuari.psicologia.17.1.173

\begin{abstract}
Resum
En el present treball, el coneixement dels esquemes emocionals en pacients deprimits permet identificar les creences que tenen sobre les emocions, pensaments erronis sobre aquestes, $i$ estarien presents en reaccions emocionals i comportaments que afecten al benestar psicològic de les persones. En aquesta línia, es va aplicar l'escala d'esquemes emocionals de Leahy, la qual consta de 50 preguntes, en una mostra de 80 pacients adults diagnosticats amb depressió, en un hospital de salut mental. Es van realitzar la validesa lingüística, la de contingut i la convergent de la prova, i es van calcular la mitjana dels factors de les variables d'estudi. A continuació, es va procedir a realitzar la correlació de Pearson entre els qüestionaris LESS i el BDI-II per comprovar la validesa convergent del primer.

Es conclou que el qüestionari LESS compta amb els paràmetres de validesa necessaris, i es replica allò esclarit per Leahy (2002). Els resultats indiquen que no existeixen diferències significatives segons edat. Segons gènere, existeixen diferències significatives als esquemes de validació, comprensió i expressió, i son les dones qui en manifesten una mitjana més alta en comparació amb els homes.
\end{abstract}

Paraules clau: esquemes, esquemes emocionals, depressió, cognició.

* Universidad de San Martín de Porres (Perú).

** Universidad Peruana de Ciencias Aplicadas (Perú). 


\title{
Resumen
}

En el presente trabajo, el conocimiento de los esquemas emocionales en pacientes deprimidos permite identificar las creencias que ellos tienen sobre las emociones, pensamientos erróneos sobre éstas, y estarían presentes en reacciones emocionales y comportamientos que afectan al bienestar psicológico de las personas. En tal sentido, se aplicó la escala de esquemas emocionales de Leahy, que consta de 50 preguntas, en una muestra de 80 pacientes adultos diagnosticados con depresión en un hospital de salud mental. Se realizaron la validez lingüística, la de contenido y la convergente de la prueba, y se calcularon los promedios de los factores de las variables de estudio. A continuación, se procedió a realizar la correlación de Pearson entre los cuestionarios LESS y el BDI-II para comprobar la validez convergente del primero.

Se concluyó que el cuestionario LESS cuenta con los parámetros de validez necesarios, replicando lo hallado por Leahy (2002). Los resultados indican que no existen diferencias significativas según edad. Según género, existen diferencias significativas en los esquemas de validación, comprensión y expresión, siendo las mujeres las que manifiestan una media más alta en estos esquemas en comparación con los varones.

Palabras clave: esquemas, esquemas emocionales, depresión, cognición.

\begin{abstract}
The knowledge of emotional schemas that depressed patients have allows us to identify the beliefs that they have about their own emotions, mistaken thoughts about these, would be present in emotional reactions and behaviours that affect the psychological well-being of people. In this paper, the Leahy Emotional Schemas Scale (LESS), that has 50 items and also created by Roberth Leahy, was taken in a sample of 80 patients diagnosed with depression in a hospital of mental health. In order to the scale to become valid in our context, it was conducted the linguistic, content, and convergent validities, calculated with average scores of each variable taken into consideration during the study. After that, it was conducted the Pearson correlation between LESS and DBI-II in order to ascertain the convergent validity of the LESS.

It was concluded that the LESS has the needed parameters in validity, reaching the same conclusion than Leahy (2002). The results of the research indicate that there aren't meaningful differences in the schemas of Validation, Comprehension and Expression according to age, and also, women tend to manifest a higher media in these schemas in contrast to men.
\end{abstract}

Key words: schemes, emotional schemes, depression, cognition. 


\section{Introducció}

Les bases teòriques dels esquemes emocionals es donen sobre les idees proposades per Leahy (2002), qui dissenyà un model dels esquemes emocionals i descriu les concepcions sobre les emocions i les estratègies del processament emocional. Proposa que les emocions com la por, la tristesa, l'ansietat i la soledat, són experiències universals, però les diferències individuals, la seua conceptualització i les estratègies de resposta determinaran com de problemàtiques arribarien a ser aquestes experiències emocionals (Leahy, 2002).

Així mateix, el terme esquemes emocionals està dirigit a referir-se als plans, conceptes i estratègies emprades en resposta a una emoció (Leahy, 2002). Manifesta que el model dels esquemes emocionals suggereix plantejar els següents punts bàsics:

- Les emocions desagradables, com ara la tristesa, la soledat, la por, l'ansietat i la còlera, són fenòmens universals.

- Els individus difereixen en la seua interpretació de la significació de les emocions.

- Aquestes interpretacions reflecteixen creences sobre la duració, controlabilitat, extremitat, complexitat, patologia i qualitat moral de les emocions i de la persona que les experimenta.

- Els esquemes emocionals negatius, tal com són reflectits per les interpretacions anteriors, exacerben addicionalment la intensitat, la negativitat $\mathrm{i}$ la duració de les emocions negatives.

- Aquestes interpretacions negatives inhibeixen l'expressió, la validació i el processament emocional.

En aquest sentit, Leahy (2002) traça un quadre del contrast entre el processament emocional problemàtic i l'adaptatiu, i estableix una comparança entre dues persones fictícies -però que, de fet, existeixen en el món real-, les quals enfronten el mateix esdeveniment de vida: «Willy Preocupado y Miguel Calmo». Ambdós saben que les seues parelles desitjables -que coincidentment tenen el mateix nom, Mary-, simplement els han deixat. Willy, preocupat, frustrat en la seua meta de comptar amb un romanç perfecte, se n'adonava de què se sentia emocionalment incòmode amb aquesta situació. Reconeixia estar pertorbat, però inicialment tenia molta dificultat per etiquetar-ne els propis sentiments. Li era complex comprendre per què se sentia tan trist. En contrast, es retracta a un Miguel Calmo plenament conscient del seu rang de sentiments -còlera, ansietat, tristesa, i inclús un toc d'esperança-. Inicialment pertorbat amb la novetat de què Mary se n'hagués anat, reconeixia que els seus sentiments no eren ni positius ni negatius, sinó plenament humans -un signe de què té una plenitud d'experiències que li ha estat proporcionant la seua família des de temps enrere-. 
En la figura 1, s'observa com la persona pot seguir tres vies separades, donada l'emoció desagradable. L'individu que en un principi atén a la seua emoció -tristesa- però que és capaç de normalitzar-la, expressar-la i experimentar-ne la validació, és menys probable que mantinga la seua tristesa. En el segon camí, mitjançant una evitació emocional i cognitiva, una persona pot recórrer a les fartades o desenvolupar dissociació per evitar els sentiments negatius, i s'enforteix la creença de què les emocions negatives no poden ser controlades o tolerades. La tercera senda entranya veure les emocions com a incomprensibles, que generen vergonya, no similars a les que altres tenen i en requereixen una simplificació. Aquestes interpretacions negatives també contribueixen a la ruminació, la preocupació i la prolongació o escalada dels sentiments negatius (Leahy, 2002).

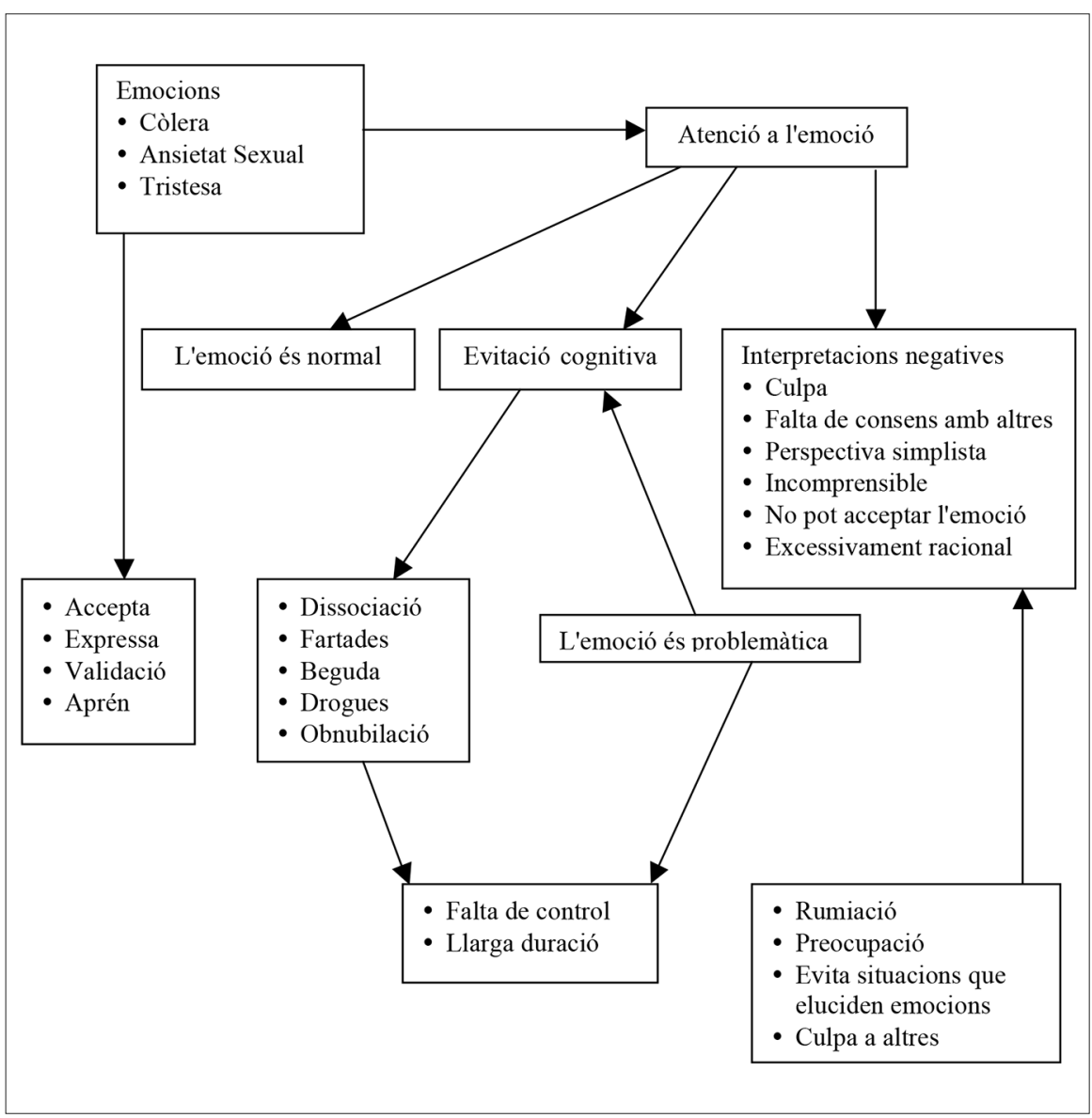

Figura 1. Esquema metacognitiu de les emocions (Leahy, 2002). 
El model d'esquemes emocionals planteja que hi ha catorze esquemes que són rellevants per al processament emocional (Leahy, 2002, 2003), i són els següients:

a. Validació. L'individu creu que existeix un públic receptiu per a les seues emocions i la validació hauria d'ajudar-lo a acceptar-se, comprendre els propis sentiments i proporcionar beneficis interpersonals.

b. Comprensibilitat. Reflexa un coneixement efectiu de les emocions i que podria ser visualitzat com elements importants de l'ansietat i la depressió.

c. Culpa i vergonya. Aquesta dimensió representa culpabilitat, vergonya i pertorbació sobre una emoció, és a dir, la creença de què u no hauria de tenir certs sentiments.

d. Simplicitat vs complexitat. La capacitat de comprendre que u pot tindre sentiments conflictius i complicats sobre u mateix i de la resta, són un senyal d'un alt nivell del funcionament de l'ego, i de la diferenciació i complexitat cognitives.

e. Relació amb valors elevats. Les emocions podrien ajudar a aclarir una de les necessitats o aconseguiments que l'individu podria desitjar continuar amb el seu propòsit, inclús amb una pèrdua. Així mateix, reconéixer la importància dels valors superiors, afirmar la legitimitat dels valors del pacient i podria ajudar-lo a reduir l'ansietat o la depressió.

f. Controlabilitat. Una característica central en l'ansietat és la percepció de què les emocions negatives intenses són incontrolables, i en el pacient amb depressió que experimenta una extrema desesperança, creu que els afectes negatius podrien aborronar-lo i durar indefinidament.

g. Inestabilitat. Per a alguns, el fet d'estar plens d'emocions intenses podria ser una experiència que els fa sentir-se plens de vida. En canvi, per a altres, la sensació d'emocions intenses sols els duu a la pèrdua de control i a la sensació de sentir-se aborronats.

h. Racionalitat $\mathrm{i}$ antiemocionalitat. La sobreracionalitat o antiemocionalitat podrien inhibir l'expressió, validació, acceptació i autocomprensió que ens permet seguir les nostres pròpies experiències emocionals.

i. Duració de sentiments forts. El model d'enfocament emocional suggereix que el fet de creure en una extensa duració de l'emoció, reflecteix dificultat per acceptar les emocions i indirectament podria estar relacionat amb la depressió o l'ansietat.

j. Consens amb altres. Reconéixer que altres tenen sentiments similars és una forma de validació i un procés que podria reduir la depressió i l'ansietat des d'aquesta perspectiva. 
k. Acceptació o inhibició. Les teories de l'enfocament emocional podrien predir que l'acceptació dels sentiments ens guien a una resolució ràpida de la depressió i l'ansietat.

I. Rumiació vs estil instrumental. El model de l'enfocament emocional afirma que el pessimisme podria ser observat com a reflex de la manca d'acceptació de l'emoció.

m. Expressió. El desig per experimentar i expressar sentiments reflecteix una acceptació de què les emocions són importants i que poden, possiblement, ampliar canvis o enteniments, per la qual cosa es considera important l'expressió emocional per tal de reduir els afectes i incrementar la comprensió i l'acceptació.

n. Culpar a altres. El model d'enfocament emocional no suggereix que culpar a altres podria ser una solució per a la depressió o ansietat, i podem afirmar que jutjar a les persones incloga jutjar-se a u mateix.

Podem suposar que si estem avaluant les característiques cognitives d'un pacient deprimit, trobaren esquemes cognitius i emocionals que influeixen en el seu afrontament diari. Aquests esquemes porten a estratègies que es tradueixen en evitació emocional i conductes d'afrontament inadequades, que n'incrementen la problemàtica. Dins la pràctica clínica s'observa a pacients que, en modificar aquests conceptes subjacents inherents al propi trastorn, aconsegueixen un canvi en les variables conductuals i cognitives, i processen adequadament les seues emocions.

El fet d'experimentar emocions i els aprenentatges cognitius sobre elles, els contextos i la forma d'interactuar, comporta a una sèrie de supòsits personals que poden traduir-se en vulnerabilitat de pacients, $i$ els generen estats de desesperança o d'incomprensió sobre les seues emocions, per això és important prendre en compte la identificació dels esquemes emocionals en el pacient. D'aquesta manera, els resultats permetran trobar els esquemes emocionals que representen en la nostra mostra d'estudi, i tractarem d'entendre com conceptualitzen les pròpies emocions i conéixer com repercuteixen en els afrontaments inadequats. Conéixer açò ens permetrà conceptualitzar cognitivament el cas que es presenta i elaborar el pla de tractament més idoni que, a través de tècniques cognitives, emocionals o experiencials, afavoririen el processament adequat dels esquemes en qüestió.

Per aquests motius, es torna fonamental comptar amb un instrument vàlid i fiable que ens ajude a conéixer els esquemes emocionals dins la població de pacients amb un diagnòstic de depressió. Aquests resultats ens possibiliten ampliar els criteris d'avaluació i orientar el camp de tractament. Finalment, es pretén contribuir, a través d'aquests resultats, a la comunitat científica amb la 
finalitat de ser un punt de partida per estandarditzar aquest instrument per a altres poblacions.

Dins les investigacions internacionals relacionades amb la teoria dels esquemes emocionals i la depressió, es troba l'estudi de Leahy, Tirch i Melwani (2012), els quals manifesten que dins els processos subjacents a una depressió, s'avaluaren tres models teòrics com ara l'aversió al risc, esquemes emocionals i flexibilitat psicològica. Es va concloure que aquests models estan significativament relacionats amb la depressió. Es va comprovar que la flexibilitat psicològica conceptualitzada com la voluntat per prendre el risc d'encarar experiències difícils estava fortament correlacionada amb les creences negatives de les emocions. El risc implicaria afrontar emocions difícils i l'habilitat per tolerar emocions negatives. Trobem les correlacions més altes d'entre les 14 dimensions del LESS (Escala d'Esquemes Emocionals de Leahy) en l'aversió al risc, relacionades amb validació, comprensió, alts valors, control i ruminació. Finalment, l'anàlisi de regressió m últiple va indicar que la depressió va ser el millor predictor de l'aversió al risc i baixa flexibilitat psicològica.

De la mateixa manera, Leahy (2002) va realitzar altre estudi amb pacients psiquiàtrics i va trobar suport empíric per a la relació entre creences mal adaptatives sobre les emocions i la psicopatologia. En correlacionar aquests valors, es va identificar que els majors nivells de depressió estaven associats amb: sentiments de culpa respecte a les emocions $(r=0.391, p<0.05)$, la creença de què les emocions no eren comprensibles $(r=-0.535, p<0.05)$, les percepcions de què les emocions implicarien una pèrdua d'autocontrol $(r=-0.348, p<0.05)$, que tindria una llarga duració $(r=0.317, p<0.05)$; no presenten consens de les pròpies emocions amb la resta $(r=-0.449, p<0.05)$ i relació amb l'esquema ruminatiu $(r=0.348, p<0.05)$. Així mateix, l'ansietat estava associada amb la culpa $(r=0.335, p<0.05)$, amb què les emocions no són comprensibles $(r=-0.535$, $p<0.05)$, creença en la falta de control $(r=-0.449, p<0.05)$ i menor acceptació de les emocions $(r=-0.343, p<0.05)$.

Igualment, Leahy (2006) va realitzar un treball sobre la metacognició i la metaemoció de la preocupació, en el qual va trobar que la majoria de les catorze dimensions de l'Escala d'Esquemes Emocionals (LESS) estaven significativament relacionades amb els cinc factors metacognitius de la preocupació, que són: vista positiva de preocupació, incontrolabilitat i perill, competència cognitiva, creences negatives i autoconsciència negativa. Açò significa que els esquemes emocionals reflecteixen la visió de què les emocions desagradables no són acceptades i estan correlacionades amb els cinc factors abans enumerats.

Tal com s'observa en les investigacions anteriors, els esquemes emocionals es correlacionen amb la baixa flexibilitat psicològica, amb els factors metacognitius de la preocupació, i amb la depressió i l'ansietat. Així, brinda suport 
teòric a la forma en com aquests esquemes emocionals ens mostren les creences errònies sobre les emocions i com estan presents significativament en els estats depressius i ansiògens. En conseqüència, es genera un camp d'explicació i una àrea per tractar del model d'intervenció cognitiva, i es conceptualitzen les idees sobre les emocions i es comprenen esquemes com ara invalidació, falta de consens, culpa, falta de valors més alts i la incomprensibilitat, que juguen tots ells un paper com a factors predictors als quadres clínics estudiats.

Trobem que en l'actualitat han sorgit diversos models psicoterapèutics amb la fi de descobrir ferramentes que permeten identificar, analitzar i avaluar estratègies idònies per ajudar a les persones que ho necessiten. Dins aquestes propostes, s'inclou la teràpia cognitiu-conductual que, segons manifesten Hawton, Salkovskis, Kira i Clark (1989; com es va citar en Lega, Caballo i Ellis, 1997), s'inicia amb les idees propostes per Lang sobre els tres sistemes de respostes relativament independents -sistemes emocional, cognitiu, i motor-, la qual cosa va aplanar el camí cap a l'acceptació de les nocions cognitives dins l'enfocament conductual. Així, l'enfocament cognitiu-conductual, després de realitzar una revisió d'evidències científiques sobre aquest tipus de teràpia, es va topar amb l'existència de nombrosos estudis que presenten un grau màxim d'eficàcia en les seues intervencions front als problemes psicològics (Gálvez, 2009).

Dins la teràpia cognitiu-conductual, observem que s'han dut a terme diversos avanços en l'explicació entre la relació i influència de la part emocional, cognitiva i conductual, des d'una perspectiva radical fins una d'integradora. D'aquesta manera, s'observa que han sorgit corrents que prenen en compte els patrons i esquemes que parteixen de l'anàlisi de la interacció de les emocions i les seues representacions cognitives. Com a part d'aquests enfocaments, ha estat Leahy (2002) qui ha buscat delinear un model d'esquemes metacognitius de les emocions, on en descriu el rol i les estratègies d'intervenció que cal emprar-se per manejar-les.

En un sentit més ampli, la concepció d'esquemes emocionals abarca no sols la manifestació emocional tàcitament, sinó que constitueix una síntesi complexa entre l'afecte, la cognició, la motivació i l'acció, que proporcionen a cada persona un sentit integrat de sí mateix i del món (Greenberg i Paivio, 2000). Aquests mateixos autors assenyalen que les emocions regulen el funcionament mental mitjançant l'organització tant del pensament com l'acció, estableixen les metes que ens són prioritàries, i ens organitzen per dur a terme certes accions concretes. Per aquest motiu, la por estableix que la meta és escapar i ens prepara per a fugir, l'enuig té a veure amb superar obstacles i ens prepara per a atacar; les metes que es persegueixen estan profundament relacionades amb la regulació dels propis vincles socials, els sentiments de felicitat ens preparen per a la cooperació, i la tristesa per a la retirada o la recerca d'ajuda. D'altra banda, les emocions estableixen les metes cap a què es dirigeixen les cognicions i les 
accions, la qual cosa converteix l'afecte en un determinat crucial de la conducta humana (Oatley i Jenkins, 1992; com es va citar en Greenberg i Paivio, 2000).

L'objectiu general de l'estudi és identificar els esquemes que presenten un grup de pacients depressius d'un hospital de la ciutat de Lima. Dins els objectius específics, es busca establir la validesa lingüística, de contingut i divergent de l'Escala d'Esquemes Emocionals (LESS) de Leahy, així com identificar i comparar els esquemes emocionals que es presenten en un grup de pacients depressius d'un hospital de la ciutat de Lima, segons l'edat.

\section{Metodologia}

\section{Participants}

La mostra s'ha obtingut mitjançant el mostreig no probabilístic de subjectes voluntaris (Hernández, Fernández i Baptista, 2010) i està composta per 80 pacients $-32 \%$ homes i $68 \%$ dones-, amb diagnòstic de depressió, les edats aproximades dels quals oscil·len entre 18 i 60 anys. Un 52.5\% (42) de la mostra té un nivell superior d'estudis, i el $47.5 \%$ (38) un nivell secundari.

Tots ells tenen menys d'un any de tractament mèdic i cap rep tractament psicològic. Procedeixen de la zona est dels districtes de la ciutat de Lima, que reben atenció especialitzada en un hospital de salut mental.

Dins els criteris d'inclusió, es van considerar els pacients amb el diagnòstic de Depressió segons el CIE-10, és a dir, una puntuació major a 7 en l'escala de Depressió de Beck. Com a criteri d'exclusió, es van deixar de banda tots aquells pacients que tenien com a diagnòstic un trastorn de personalitat associat, quadre psicòtic o deficiències cognitives.

\section{Instruments}

\section{Inventari de Depressió de Beck (BDI-II)}

Aquesta prova és útil per ser aplicada en població normal i psiquiàtrica, i pot ser a més administrada a partir dels 13 anys. Així, els ítems de l'instrument són puntuats segons una escala de $0 \mathrm{a} 3 \mathrm{i}$ la puntuació total màxima que es pot obtenir és de 63. Cal considerar que en cas de què l'examinand marque més d'una alternativa de resposta, s'empra l'alternativa amb el valor més alt (Brenlla i Rodríguez, 2006). Els símptomes que avalua són: tristesa, pessimisme, fracàs, pèrdua del plaer, sentiment de culpa, sentiments de càstig, disconformitat amb u mateix, autocrítica, pensaments o desitjos suïcides, plors, agitació, 
pèrdua d'interès, indecisió, desvalorització, pèrdua d'energia, canvi en els hàbits de son, irritabilitat, canvi en l'apetit, dificultat de concentració, cansament $o$ fatiga, i pèrdua d'interès en el sexe. Pot ser autoaplicada de forma individual o col-lectiva, i la mitjana de temps per resoldre-la és de 10 a 15 minuts. És una prova de llapis i paper.

Entre les versions en castellà, trobem l'adaptació argentina que es va dur a terme a través del procediment de traducció inversa, la revisió especialitzada del contingut de les traduccions, l'administració de la prova obtinguda per aquests procediments en una mostra pilot, i l'estudi de les propietats psicomètriques obtingudes en aquesta versió argentina. Quant a la fiabilitat, el coeficient alfa de Cronbach de l'inventari va ser de .88 per a la mostra psiquiàtrica i de .86 per a la mostra normal. En ambdues mostres totes les correlacions test-retest de 7 a 10 dies després d'administrar la prova en un grup de 17 pacients externs, va ser de .90 . En la població general, es va constatar una correlació de .86 que indica una estabilitat important del BDI-II a través del temps. Pel que fa a la validesa convergent, les dades indiquen que el BDI-II està correlacionat positivament amb l'Escala de Depressió del MMPI-II i amb la del SCL-90-R (Brenlla i Rodríguez, 2006).

Pel que fa als estudis peruans, Carranza (2011) va presentar les propietats psicomètriques de l'Inventari de Depressió de Beck amb 2005 estudiants d'universitats tant privades com estatals de Lima Metropolitana. Es va confirmar la validesa de contingut amb la $V$ d'Aiken, on tots els ítems van obtenir un índex de significança de $p>0.01$; la validesa de constructe mitjançant l'anàlisi de l'ítem-test, en què tots els ítems van obtindre correlacions amb un índex de significança de $p>0.01$ i mitjançant l'anàlisi factorial confirma l'existència de dos components: somàtic-motivacional i cognitiu-afectiu. Així mateix, la confiabilitat es va realitzar mitjançant el Coeficient Alpha de Cronbach i es va obtindre .878 , la correlació de parells i imparells va ser de $r=0.803(p>0.01)$, tècnica de les dues meitats amb un índex de .799 i test-retest $(r=0.996, p>0.01)$. D'altra banda, l'establiment de barems indica les categories de mínim (0-6 punts), lleu (7-11 punts), moderat (12-16 punts) i sever (17-63).

\section{Escala d'Esquemes Emocionals-LESS de Leahy (2002)}

Aquesta escala va ser creada per Leahy en l'any 2002, i pren com a base la teoria d'esquemes emocionals proposada per aquest mateix autor. S'aplica a persones adultes i està composta per 50 expressions. Aquest instrument té com a objectiu identificar 14 esquemes emocionals, entre què es troben: validació, comprensibilitat, culpa i vergonya, simplicitats vs complexitat, relació amb valors elevats, controlabilitat, insensibilitat, racionalitat i antiemocionalitat, duració de sentiments forts, consens amb altres, acceptació o inhibició, rumiació 
vs estil instrumental, expressió i culpar a altres (Leahy, 2002). Segons els processos estadístics, els ítems 22 i 43 no van ser inclosos en els 14 esquemes. La fiabilitat Alfa de Cronbach va ser de $.809(n=379)$.

Les respostes donades per cadascú dels subjectes poden ser considerades d'1 a 4 punts, d'acord amb la intensitat de l'emoció en la seua situació actual. Les opcions varien entre 4 alternatives - molt fals per a mi, un poc fals per a mi, un poc vertader per a mi i molt vertader per a mi-. Aquesta escala compta amb reactius amb qualificació directa $(4,6,8,11,13,14,15,17,18,21,22,23,24$, $26,30,31,32,34,35,37,38,39,40,41,42,43,46,47,48)$ i amb qualificació indirecta $(1,2,3,5,7,9,10,12,16,19,20,25,27,28,29,33,36,44,45,49$, 50).

No existeixen evidències de la validesa ni fiabilitat en el nostre mitjà. Per això, un dels objectius d'aquest estudi és validar-la en pacients amb depressió.

\section{Procediment}

És una investigació amb un disseny no experimental, transaccional i descriptiu (Hernández, Fernández i Baptista, 2010). Els pacients que van formar part de la mostra van firmar un consentiment informat, el qual va garantir la confidencialitat i la llibertat d'abandonar l'estudi si així ho decidia.

Per adaptar l'escala de Leahy (2002) al tipus de participants de l'estudi, es va aplicar l'escala a un grup pilot format per 20 pacients entre homes i dones. Es va iniciar amb la traducció de l'escala de l'anglès al castellà, per una psicòloga de professió que domina ambdós idiomes i té com a llengua materna el castellà. Així mateix, s'ha realitzat novament la conversió a l'anglès per altre professional de la salut, qui també domina ambdós idiomes, i aquesta redacció es va presentar a l'autor original de la prova, el qual va demostrar acceptació a tots els ítems de l'escala. Es va realitzar la validesa de contingut pel criteri de jutges, amb la participació de huit psicòlegs especialistes en teràpia cognitivaconductual, qui ostentaven el grau de magister i a qui prèviament se'ls va enviar una sol-licitud per ser jutges, cartilla d'instruccions generals i l'instrument amb les respectives preguntes. Per a això, van prendre en compte la claredat, congruència i domini de constructe dels ítems.

Les dades obtingudes en aquests mesuraments van ser processats estadísticament, mitjançant el paquet estadístic per a les Ciències Socials SPSS -versió 21.0 per a Windows-. Es van triar els estadístics d'acord als propòsits d'estudi: per confirmar la validesa i fiabilitat de l'escala, i estadístics descriptius, entre els quals la freqüència, mitjana, desviació típica i de caràcter comparatius per als resultats. 


\section{Resultats}

Aquesta secció s'enceta amb l'exposició dels resultats de l'adaptació lingüística de l'Escala d'Esquemes Emocionals - LESS (Leahy, 2002) i, posteriorment, els descriptius i inferencials obtinguts a partir de les comparacions.

La validesa lingüística es va treballar mitjançant la metodologia de traducció directa i inversa (traducció-retraducció). L'última versió va ser revisada per l'autor de l'escala Leahy (2002), qui, com ja hem esmentat anteriorment, va mostrar acceptació amb els continguts de cadascun dels ítems, amb l'excepció de l'ítem 6 pel que va suggerir que se suprimís una paraula: «I think it's ok to cry or yett and let out my feelings»-podria eliminar-se yell-, fet que no va desqualificar la traducció realitzada de l'ítem.

Posteriorment, es va calcular la validació de contingut per criteri de jutges de l'Escala, mitjançant el coeficient $V$ d'Aiken amb una significança de 0.05. Els coeficients de validesa obtinguts es troben dins els rangs acceptats per a proves psicològiques $(V=.80)$, la qual cosa confirma la validesa de cadascun dels ítems.

Per a l'anàlisi de la fiabilitat, es va emprar el Coeficient Alfa de Cronbach. En la taula 1, es mostra que els esquemes Comprensibilitat, Visió simple de les emocions, Control i Racional són majors a .5 ubicats com a suficients, tal com ho assenyala Nunnally (1967).

TAULA 1

Anàlisi de la consistència interna $i$ fiabilitat de l'Escala d'Esquemes Emocionals de Leahy (LESS)

\begin{tabular}{|lc|}
\hline ESQUEMES & ALFA DE CRONBACH \\
\hline Validació &, 356 \\
Comprensibilitat &, 641 \\
Culpabilitat &, 486 \\
Visió simple de les emocions &, 515 \\
Valors &, 056 \\
Control &, 610 \\
Insensibilitat &, 171 \\
Racional &, 505 \\
Duració &,- 467 \\
Consens &, 493 \\
Acceptar &, 444 \\
Ruminació &, 297 \\
\hline
\end{tabular}


Quant als resultats descriptius, els participants obtenen una mitjana més alta en l'esquema d'Acceptació o inhibició (17.09), Rumiació vs estil instrumental (13.10). les mitjanes més baixes s'observen als esquemes d'Insensibilitat (4.90) i Duració dels sentiments forts (5.15).

Es va dur a terme una anàlisi de comparació de les puntuacions obtinguts als esquemes emocionals en els pacients depressius segons sexe, per a la qual es va emprar l'estadístic $t$ d'Student. Els resultats indiquen que existeixen diferències estadísticament significatives als esquemes de Validació $(t=2.680, g l=78$, $p=.001)$, Comprensió $(t=-2.524, g l=78, p=.001)$ i Expressió $(t=-2.036, g l=78$, $p=.001)$. Hi són les dones qui manifesten una mitjana més alta en aquests esquemes en comparació amb els homes.

Amb la finalitat de comprovar l'objectiu d'investigació, es va realitzar una segona anàlisi de comparació, aquest cop segons edat. Per a açò, s'empra l'estadístic $t$ d'Student. Els resultats indiquen que no existeixen diferències significatives segons edat.

Pel que fa a l'anàlisi correlacional, es va trobar l'existència de correlació positiva i significativa entre: BDI-II Total amb Culpai vergonya ( $r=.353$, $p<.01)$, Simplicitatvs complexitat $(r=.309, p<.01)$ i Rumiació vs estil instrumental $(r=.485, p<.01)$. igualment, es va comprovar una correlació negativa i significativa entre: Depressió amb Validació $(r=-.462, p<.05)$, Comprensió $(r=-.484, p<.05)$, relació amb els valors més alts $(r=-.353, p<.05)$, Controlabilitat $(r=-.447, p<.05)$, Consens amb la resta $(r=-.353, p<.05)$ i Acceptació o inhibició ( $r=-.394, p<.05)$. Finalment, es va comprovar que no existeix correlació entre el BDI amb Insensibilitat, Racionalitat-antiemocionalitat, Duració dels sentiments forts, Expressió i Culpar a la resta. Sobre la base dels resultats obtinguts, podem concloure que el qüestionari LESS compta amb els paràmetres de validesa necessaris, i replica allò trobat per Leahy (2002), resultat que es pot apreciar a la taula 2 . 


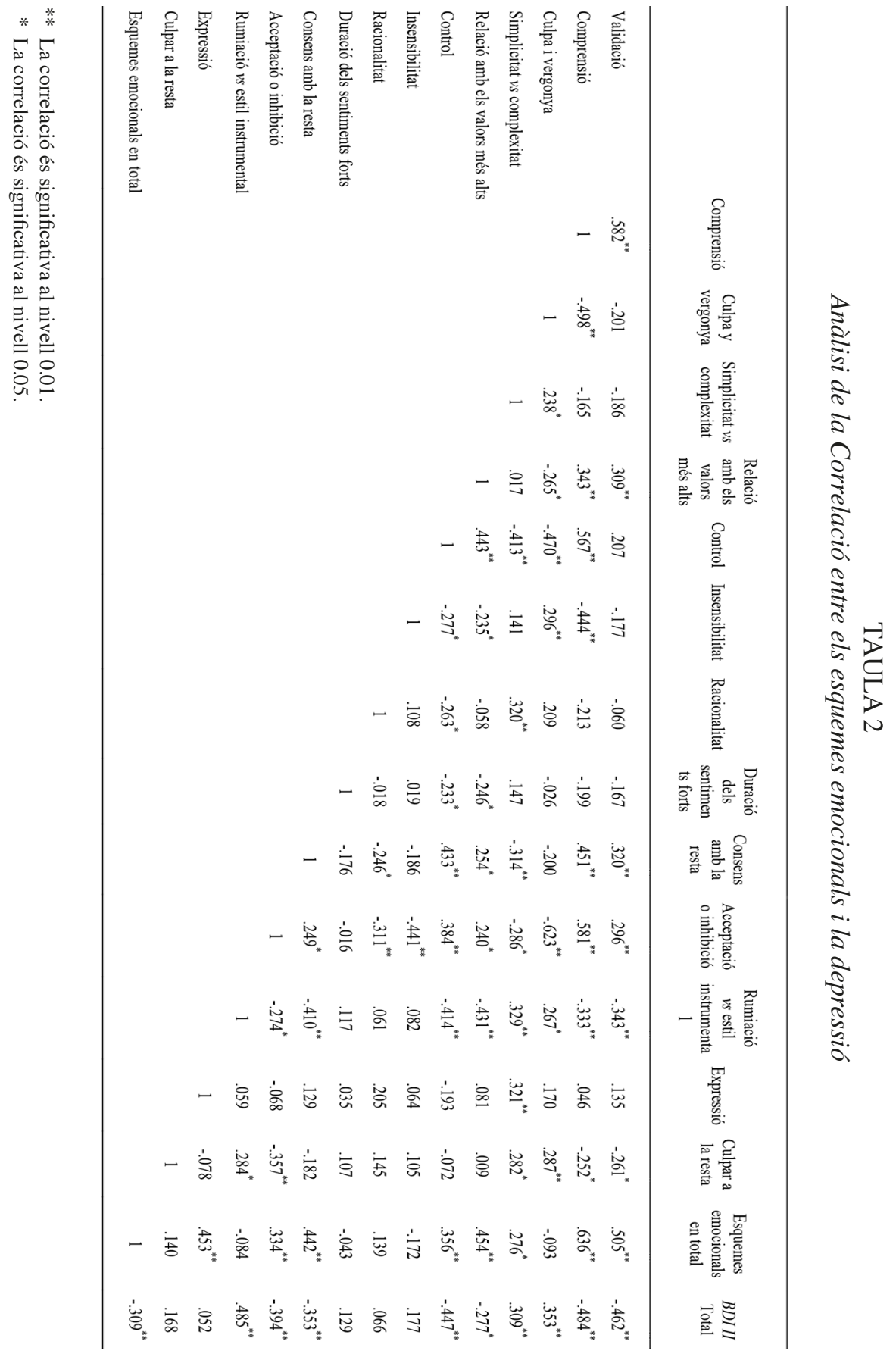




\section{Discussió}

En primer lloc, cal assenyalar que l'Escala d'Esquemes Emocionals de Leahy (LESS) posseeix els paràmetres de validesa necessaris per mesurar els esquemes emocionals en grups similars a la mostra estudiada, donat que s'observen resultats concordants amb els teòricament esperats. Aquests esquemes reflecteixen la importància del processament cognitiu en el tractament de la depressió i l'ansietat (Leahy, 2002).

Quant als resultats descriptius, els participants obtenen una mitjana més alta en l'esquema d'Acceptació o inhibició i Rumiació, i les més baixes als esquemes d'Insensibilitat i Duració dels sentiments forts. Hi ha presència dels catorze esquemes en la mostra seleccionada, els quals, junt als indicadors depressius en nivells de mínim i lleu, estan més relacionats a esquemes com ara Validació, Comprensió de les emocions i Relació amb valors més alts. Els indicadors en depressió elevada i severa es presenten en major freqüència en esquemes de Rumiació, Visió simple de les emocions i Culpa. Açò corrobora i permet identificar amb major detall com actuen aquests esquemes segons el nivell depressiu presentat en el grup avaluat.

El present treball mostra l'existència d'una correlació positiva i significativa entre depressió i els esquemes de Culpa i vergonya, Visió simple de les emocions i Ruminació. Igualment, comprovem la presència d'una correlació negativa i significativa entre depressió i els esquemes de Validació, Comprensió, Relació amb els valors més alts, Controlabilitat, Consens amb la resta i Acceptació o inhibició. És a dir, són inversament proporcionals: a major depressió, menor puntuació en els esquemes mencionats. Açò replica allò esbrinat per Leahy (2002), el qual proporciona un suport empíric de cara a la relació entre creences mal adaptatives sobre les emocions i la psicopatologia. És així com aquest autor, en el seu estudi realitzat al 2002, correlaciona les puntuacions del LESS amb l'inventari de depressió de Beck i identifica que majors nivells de depressió estaven associats amb els sentiments de culpa respecte a les emocions. S'observa que en ambdós treballs, els esquemes de culpa sobre les emocions, ruminació, incomprensió de les emocions, incontrolabilitat i falta de consens estan fortament relacionats amb nivells alts de depressió. L'escala LESS d'esquemes emocionals ha sigut correlacionada de forma directa amb la baixa flexibilitat psicològica, ja que s'identifiquen la invalidació, la falta de consens, la culpa, la falta dels valors més alts i la incomprensibilitat de les emocions (Leahy, Tirch i Melwani, 2012).

Els resultats de la investigació indiquen que els pacients depressius presenten esquemes de culpa en experimentar les emocions de tristesa, de la mateixa manera que no comprenen i tracten d'evitar aquesta emoció mitjançant una visió simple de les mateixes. Ja Linehan (1995) en la seua teràpia dialèctica esmenta 
que la capacitat per coordinar sentiments conflictius és un aconseguiment essencial en el propi sistema tal que un error en aquesta coordinació podria resultar en un estat d'ànim volàtil (Leahy, 2002; 2010). Per tindre culpa i vergonya, i una visió simple de les emocions, la persona no es connecta amb els valors que podrien significar algunes reaccions que experimenta, $i$ tampoc aconseguir una comprensió de les pròpies emocions si únicament tracta d'invalidar-les. Açò contribueix a l'evitació de les emocions i per tant a l'ús d'estratègies d'afrontament inadequades front allò experimentat. L'aprenentatge sobre les emocions, la seua importància o el desinterès percebut per les seues necessitats han pogut contribuir al fet de vore les emocions com a simples. Els pares poden facilitar o inhibir el desenvolupament de regles apropiades de demostració de les emocions, el coneixement de les emocions conflictives o ambivalents, $\mathrm{i}$ la regulació de les emocions. De la mateixa manera, el temperament innat-p.e. la predisposició cap a la inhibició o cap a una alta activació- també pot determinar el derroter de la socialització emocional (Kaga, 1992, com es va citar en Manrique, 2003).

La ruminació, per la seua banda, es troba molt ben documentada en els trastorns ansiosos i depressius com un estil de pensament que pertorba. És així com la rumiació està relacionada a una gran depressió i ansietat (Nolen-Hoeksema, 2000; Papageourgiou i Wells, 2001). Freqüentment es creu que la preocupació i rumiació prepara per al pitjor i ajuda a trobar una solució als propis problemes (Leahy, 2002; 2015).

No obstant això, l'evidència suggereix que la preocupació pot tenir un efecte negatiu sobre el processament emocional que segueix a l'estrès i al trauma (Butler, Wells i Dewik, 1995; Wells i Papageorgiou, 1995; Wells i Papageorgiou, 2001). Més generalment, breus períodes de preocupació semblen estar associats amb un increment en la intrusió de pensaments (Borkovec, Robinson, Prozinsky i DePree, 1983, com es va citar en Wells, 2004).

La preocupació contribueix als pensaments intrusius, i la perseveració és problemàtica degut a què focalitza l'atenció en la informació negativa i nega la consolidació d'informació positiva necessària per al canvi de creences. Tal com suggereix l'evidència empírica, açò pareix dur a una amplificació de les respostes d'estrès sota certes circumstàncies (Wells, 2004; 2009).

Als models de vulnerabilitat cognitiva de la depressió, la rumiació ha plantejat que les diferències individuals en les respostes cognitives als estats d'ànim poden determinar si aquests inicien una escalada cap a trastorns clínics més severs i crònics. Per exemple, s'ha suggerit que un cop establert un estat d'ànim disfòric, pot ser mantingut i exacerbat per biaixos congruents amb l'estat d'ànim en la memòria i l'atenció (Segale i Ingran, 1994, com es va citar en Manrique, 2003). Particularment, hi ha una creixent evidència de què el neuroticisme està associat amb un risc per a la disfòria i la depressió clínica, i que l'estil rumiatiu pot explicar l'efecte del gènere $i$ del neuroticisme en la vulnerabilitat per als 
episodis de disfòria (Nolan, Roberts i Gotlib, 1998; Roberts, Gilboa i Gotlib, 1998; Vergara-Lopez, Lopez-Vergara i Roberts 2015).

De la mateixa manera, es va trobar una correlació negativa i significativa entre Depressió i validació, comprensió, relació amb els valors més alts, controlabilitat, consens amb la resta, i acceptació o inhibició. Açò vol dir que quant més valide el pacient les pròpies emocions com a experimentables, acceptable i que no ho negue, comprengue i ho relacione amb els valors que presenta, entenga que altres persones també passen per la seua mateixa experiència emocional, crearà un $\mathrm{m}$ ajor sentit $\mathrm{i}$ en replantejarà els estats emocionals. Per això, veiem que els esquemes esmentats més amunt estan correlacionats negativament amb els estats depressius. L'experiència de l'emoció, l'empatia i la validació són claus durant les primeres etapes del procés terapèutic (Greenberg i Paivio, 2000).

El consens de què succeeix amb les emocions són bases en el procés d'intervenció terapèutica, un dels aspectes bàsics és proveir suport i fer sentir que les respostes del client front les crisis són les més comprensibles donada la situació, on es pot emprar la paraula comú per descriure eixes reaccions i es posa èmfasi en què altres també actuen del mateix mode, a l'hora que busquen consens (James i Gilliland, 2013).

Molts pacients poden interpretar que no han de presentar cap tipus d'emoció negativa, i aquest error els pot dur a no entendre les pròpies emocions i els significats que poden aconseguir en clarificar la funció de les emocions. A major validació, menor nivell depresògen, i s'entén que l'acceptació és un recurs important en la conceptualització de les emocions, per la qual cosa qualsevol estratègia que invalide seria contraproduent per a les estratègies d'afrontament.

La tercera senda comporta veure les emocions com incomprensibles, que generen vergonya, no similars a què altres tenen, i que en requereixen una simplificació. Aquestes interpretacions negatives també contribueixen a la ruminació, la preocupació i a prolongació o escalada dels sentiments negatius (Leahy, 2003; Leahy, 2011; Vergara-López, Kyung, Detschmer i Roberts, 2014).

És important que els pacients també identifiquen els propis valors, en el procés de conceptualitzar-ne les emocions l'evitació cognitiva pot veure les emocions com incomprensibles. No obstant això, el seu replantejament amb un nou sentit de valor, permet acceptar i validar aqueixes emocions.

Moltes de les emocions són el resultat d'avaluacions automàtiques que es fan sobre el significat de les situacions en relació al propi benestar. Són el resultat de les pròpies valoracions sobre la rellevància que les situacions tenen, en funció d'allò que resulta interessant (Fridja, 1986, com es va citar en Greenberg i Paivio, 2000).

L'èmfasi en els valors superiors podria ser derivat des d'un model cognitiu existencial del processament emocional, tal com assenyalava Víctor Frank, qui 
visualitzava les experiències evocatives emocionals com un potencial d'obertura dins la clarificació de valors (Leahy, 2002).

Podríem inferir que en la mostra de pacients del present estudi, l'expressió de les emocions han format part d'un repertori de resposta de major acceptació i validació quant a la seua conceptualització en les dones en comparació amb els homes. Açò resulta interessant en el context d'investigar com es comporten aquests esquemes en poblacions no clíniques a través de l'observació dels esquemes característics en funció del gènere.

Amb la investigació realitzada, s'adapta al castellà la prova d'Esquemes Emocionals de Leahy (2002), i n'és rellevant el seu ús en poblacions amb el mateix idioma. De la mateixa manera, es podran explorar els esquemes en la població clínica, ja que presenten característiques similars en les pròpies respostes cognitives, afectives i comportamentals. De per sí, aquests resultats marquen una pauta avaluativa i interventiva que contribueix amb el model cognitiu-conductual, a l'hora que enriqueix el marc teòric i empíric de les creences respecte a les emocions. D'una banda, avaluativa perquè permet explorar esquemes emocionals relacionats amb la depressió, la qual cosa constitueix una línia d'exploració en les entrevistes inicials i en la conceptualització dels casos. D'altra, interventiva ja que segons els esquemes identificats, les estratègies conductuals-congnitives i/o experiencials permetran corregir-los i desenvolupar recursos afrontatius que milloren el processament emocional.Aquesta prova, amb la seua validesa, contribueix al suport empíric de la relació entre els esquemes emocionals i la psicopatologia.

Queda l'oportunitat de dur a terme altres treballs d'investigació que permeten estudiar aquesta variable amb diverses mostres clíniques i grups de la població, ja que és un tòpic d'importància en el quefer psicològic, tant a nivell preventiu com en el psicoterapèutic.

\section{Referències}

Brenlla, M. i Rodriguez, C. (2006). Adaptación argentina del Inventario de Depresión de Beck (BDI-II). Buenos Aires: Paidós.

Butler, G.; Wells, A. i Dewick, H. (1995). Differential effects of worry and imagery after exposure to a stressful stimulus: a pilot study. Behavioural and Cognitive Psychotherapy, 23, pp. 45-56.

Carranza, R. (2011). Propiedades Psicométricas del Inventario de Depresión de Beck Para Universitarios de Lima. Recuperado de $<$ http://papiros.upeu.edu. pe/bitstream/handle/123456789/103/CSS10Articulo.pdf?sequence=1 $>$.

Gálvez, J. (2009). Revisión de evidencias científicas de la terapia cognitiva conductual. Medicina natural, 3(1), pp. 10-16. 
Greenberg, L. i Paivio, S. (2000). Trabajar con las Emociones en Psicoterapia. Barcelona: Paidos.

Greenberg, L. (2000). Emociones: una Guía Interna, Bilbao: Desclée de Brouwer.

Hernández, C.; Fernández, C. i Baptista, P. (2010). Metodología de la investigación. (4a. Ed.). México D.F.: Mc Graw-Hill.

James, R. i Gilliland, B. (2013). Crisis Intervention Strategies. Belmont: Brooks/ColeCengage Learning.

Leahy, R. (2002). A model of emotional schemas. Cognitive and behavioral practice, 9, pp. 177-190.

Leahy, R. (2003). Cognitive Therapy Techniques. A practitioner's guide. New York: The Guilford Press.

Leahy, R. (2006) Meta-Cognition and Meta-Emotion in Worry. Miami: ADAA 26th Annual Conference.

Leahy, R. L. (2010). Emotional Schemas in Treatment Resistant Anxiety. En D. Sookman i R. L. Leahy, Treatment Resistant Anxiety Disorders: Resolving Impasses to Symptom Remission, pp. 135-160. New York: Routledge.

Leahy, R. L. (2011). Emotional Schema Therapy: A Bridge over Troubled Waters. En J. Herbert i E. Forman, Acceptance and Mindfulness in Cognitive Behavior Therapy.

Leahy, R. L. (2015). Emotional Schema Therapy. New York: Guilford Press.

Leahy, R.; Tirch, D. i Melwani, P. (2012). Processes Underlying Depression: Risk Aversion, Emotional Schemas and Psychological Flexibility. International Journal of Cognitive Therapy, 5(4), pp. 362-379.

Lega, L.; Caballo, V. i Ellis, A. (1997). Teoría y práctica de la terapia racional emotivo-conductual. Madrid: Siglo XXI.

Linehan, M. M. (1995). Comprendiendo el Trastorno límite de la personalidad: Manual sobre el enfoque dialéctico. New York: Guilford Press.

Manrique, E. (2003). Antecedentes tempranos y Modalidades de vulnerabilidad cognitiva para la depresión. Revista de Psiquiatría y Salud Mental Hermilio Valdizán, 4(2), pp. 43-62.

Manrique, E. i Aguado, H. (2006). Esquemas Emocionales, Evitación Emocional y Proceso de Cambio en Terapia Cognitiva-Conductual. Revista de Psiquiatría y Salud Mental Hermilio Valdizán, 7(1), pp. 362-379.

Mezulis, A. H.; Abramson, L. Y.; Hyde, J. S. i Hankin, B. L. (2004). Is there a universal positivity bias in attributions? A meta-analytic review of individual, developmental and cultural differences in the self-serving attributional bias. Psychological Bulletin, 130(5), pp. 711-747, doi: 10.1037/00332909.130.5.711.

Nolan, S. A.; Roberts, J. E. i Gotlib, I. H. (1998). Neuroticism and ruminative response style as predictors of change in depressive symptoms. Cognitive Therapy and Research, 22, pp. 445-455. 
Nolen-Hoeksema S. (2000). The role of rumination in depressive disorders and mixed anxiety/depressive symptoms.Journal of Abnormal Psychology, 109(3), pp. 504-511.

Nunnally, J. C. (1967). Psychometric theory. New York: McGraw Hill.

Papageorgiou, C. i Wells, A. (2001). Metacognitive beliefs about rumination in recurrent major depression, Cognitive and Behavioral Practice, 8(2), pp. 160-164, doi: 10.1016/S1077-7229(01)80021-3.

Roberts, J. E.; Gilboa, E. i Gotlib, I. H. (1998). Ruminative response style and vulnerability to episodes of dysphoria: Gender, neuroticism, and episode duration. Cognitive Therapy and Research, 22, pp. 401-423.

Vergara-Lopez, C. Lopez-Vergara, H. i Roberts, J. E. (2015). Testing a «content meets process» model of depression vulnerability and rumination: Exploring the moderating role of set-shifting deficits. Journal of Behavior Therapy and Experimental Psychiatry, 50, pp. 201-208. doi:10.1016/j. jbtep.2015.08.002.

Vergara-Lopez, C.; Kyung, Y.; Detschmer, A. i Roberts, J. E. (2014). Testing the Cognitive Catalyst Model with idiographic content: Rumination moderates the association between self-discrepancies and depressive symptoms. Journal of Experimental Psychopathology, 5, pp. 351-362, doi: 10.5127/ jep.038313.

Wells, A. i Carter, K. (2001). Further tests of a cognitive model of generalized anxiety disorder: Metacognitions and worry in GAD, panic disorder, social phobia, depression, and nonpatients. Behavior Therapy, 32, pp. 85-102.

Wells, A. (2004). Anxiety Disorders: Metacognition and Change. En Leahy (Ed.), Roadblocks in Cognitive-behavioral Therapy. Nueva York: Guilford.

Wells, A. (2009). Metacognitive therapy for anxiety and depression. New York: Guilford Press

Wells, A. i Papageorgiou, C. (1995). Worry and the incubation of intrusive images following stress. Behaviour Research and Therapy, 33, pp. 579-583.

Wells, A. i Papageorgiou, C. (2001). Brief cognitive therapy for social phobia: a case series. Behaviour Research and Therapy, 39, pp. 713-720.

Data de recepció: $30-08-2016$

Data d'acceptació: 22-12-2016 